\title{
Understanding the Long-Term Changes in Groundwater Level-A Tale of Highly Urbanized City
}

\author{
Mst Ilme Faridatul ${ }^{1 *}$, Md Niamul Bari ${ }^{2}$ \\ ${ }^{1}$ Department of Urban and Regional Planning, Rajshahi University of Engineering \& Technology, Rajshahi, Bangladesh \\ ${ }^{2}$ Department of Civil Engineering, Rajshahi University of Engineering \& Technology, Rajshahi, Bangladesh \\ Email: *mifaridatul@urp.ruet.ac.bd
}

How to cite this paper: Faridatul, M.I. and Bari, M.N. (2021) Understanding the LongTerm Changes in Groundwater Level-A Tale of Highly Urbanized City. Journal of Geographic Information System, 13, 466-484. https://doi.org/10.4236/jgis.2021.134026

Received: June 14, 2021

Accepted: July 30, 2021

Published: August 2, 2021

Copyright () 2021 by author(s) and Scientific Research Publishing Inc. This work is licensed under the Creative Commons Attribution International License (CC BY 4.0).

http://creativecommons.org/licenses/by/4.0/

\section{(c) (i) Open Access}

\begin{abstract}
The rapid drop in the groundwater level has raised concerns in the sustainable water management plan in many cities of the world. It is important to understand the underlying factors of such depletion. To improve knowledge of the changes in groundwater, this study investigates a long-term perspective of urbanization, and evaluates the influence of several factors including land cover, water use, and abstraction. Multi-year land cover maps are used to detect urbanization and land cover types. Hotspot analysis and correlation-regression are applied to assess the relationship between changes in groundwater and the driving factors. The investigations confirm that an extensive withdrawal of groundwater due to urbanization results in a progressive drop in the water level. However, the major industrial and commercial zone shows the consistent hotspot of groundwater depletion. The results indicate that groundwater abstraction and types of water use have a high influence on the changes in urban groundwater.
\end{abstract}

\section{Keywords}

Groundwater, Urbanization, Land Cover, Water Abstraction, Water Use

\section{Introduction}

Groundwater is one of the important life-sustaining resources [1], and main sources of water supply in many urban areas [2] [3] [4]. It consists of liquid water located below the ground surface, and includes soil water either above the water table or as groundwater below the water table [5].

Most of the megacities in the world largely depend on this water for drinking and food production [6] [7]. It should be noted that dependence on groundwater 
is increasing in response to urbanization and an increase in per capita water usage [8]. Mismanagement and high abstraction of groundwater resources have led to the depletion of water level and aquifer disaster in many cities across the world [9].

Rapid urbanization and land use land cover changes have continued to affect both the quantity and quality of this freshwater [10] [11] [12]. Urbanization alters the natural earth surfaces and brings in several ecological and environmental problems [13] [14]. The changes in land cover and surface sealing modify the rate of infiltration and the natural drainage systems [15]; such changes affect the aquifer recharge, base flow and quality of this water [10]. Anthropogenic activities and climate change also have an impact on the groundwater, which results in the depletion of water level and saltwater intrusion [16]. Moreover, over-extraction of groundwater results in a rapid drop in the water level [17] [18]. The global water demand has been increasing and continues to grow. In the current decade, the withdrawal of groundwater raised nearly 8 times [19]. The increase in urban population and economic activities has boosted per capita water demand and its use [20]. As water demand is increasing, this freshwater is going to be exploited extensively [2] [21], therefore, it is a high concern in many parts of the world [22] including Dhaka, Bangladesh.

The megacity, Dhaka accommodates nearly 18.23 million population [23], and one of the fastest-growing and densely populated cities in the world [24] [25]. Rapid urbanization has resulted in a high population density of $23,234 / \mathrm{Km}^{2}$ [26]. The city is extensively dependent on the groundwater water [24] [27] [28] [29] [30]. The heavy reliance on groundwater water for all types of water usage has brought about a high abstraction of this freshwater. It seemed that the over-extraction has resulted in a rapid decline in the water table [31]. In the context of rapid urbanization, the concern about groundwater water depletion is growing, therefore, many studies [17] [21] [32] have been conducted to assess the impacts of urbanization on groundwater water recharge, water level, and water quality. The previous studies reported that the changes in the quantity and quality of the groundwater water systems are associated with urbanization, climate change, and human activities.

To date, many studies have been conducted related to urbanization and groundwater. However, the investigations over Dhaka City have been limited by inadequate spatial coverage of the groundwater water level monitoring data. In the study of Akther, Ahmed [33] and Hoque, Hoque [17], the changes in the groundwater level of Dhaka were presented by hydrographs of a few monitoring wells. The studies elucidated the global trend of water level declination in Dhaka. Arfanuzzaman and Atiq Rahman [11] indicated that an increase in the water demand influences the extensive withdrawal of water that resulted in a high drop in the water table. Using time-series data the study assumed that water levels drop because of a gradual increase in the numbers of water abstraction wells. However, the study lacked to clarify the local spatial changes and their interactions with water use. Moreover, the study of Restiani [31] indicated that heavy 
reliance on groundwater in the Dhaka city brought about over-extraction of this freshwater thus resulted in a rapid drop in the water table.

Although several studies have been conducted in the Dhaka city, the studies were constrained by relatively short temporal scales of study. Moreover, no attempts have yet been made to relate local spatial changes in the water level and their interaction with urban growth factors. Noted from the literature review [10] [11] [12] that urban land cover changes also affect the groundwater systems. Thus, this study aims to consider the influences of both urban land cover characteristics and water abstraction on the groundwater levels. Dhaka city faces rapid urbanization and a high drop in the water levels. An understanding of the local spatial changes is important for mitigating water scarcity. Moreover, monitoring urban expansion and evaluating their impact on water resources is significant for sustainable water resource management [34]. With a focus on urbanization, first, this study aims to present a long-term overview of the land cover changes using the classification of satellite images. Second, to present spatial and temporal variations in the water level using the aquifer static water level (SWL) database. Third, to identify the hotspots of water level changes using spatial statistical analysis. Finally, aims to assess the local spatial influences of land cover characteristics and types of water abstraction on the water level using the ordinary least square regression (OLS) model.

\section{Study Area and Datasets}

Dhaka, the megacity of Bangladesh is selected as the study site (Figure 1(a)). It is located in the central part of Bangladesh and is situated between latitudes $23.40^{\circ}$ to $23.97^{\circ}$ and longitudes $90.20^{\circ}$ to $90.59^{\circ}$. The climate of the study area is characterized by a humid sub-tropical monsoon. The temperature in summer ranges between $28^{\circ} \mathrm{C}$ to $34^{\circ} \mathrm{C}$ and $10^{\circ} \mathrm{C}$ to $21^{\circ} \mathrm{C}$ in winter. The annual average precipitation is $2000 \mathrm{~mm}$ of which $80 \%$ occurs in the monsoon. Dhaka accommodates nearly 18.23 million population (UN, 2016). It is one of the dense and fastest-growing megacities in the world [24] [25]. With an increase in the urban population, water demand gradually increases [11] which results in over-extraction of groundwater water. Dhaka is one of the groundwater water-dependent cities in the world [35], therefore, nearly $80 \%$ of the supplied water comes from groundwater and the remaining water comes from surface water [24] [27] [28] [29] [30]. The heavy reliance on groundwater water for all types of water usage has brought about the over-extraction of this freshwater. Therefore, a rapid decline in the water table is observed, especially in the zones of textile industries [31]. The study area is surrounded by a network of rivers and canals [25], but, with an increase in urbanization and industrial development, the surface water bodies have become increasingly polluted [24]. Therefore, the rivers are not suitable for the supply of drinking water [28] [36]. Due to the lack of potable surface water, the dependency on the groundwater water has continued to increase that resulted in a gradual rise in the installation of the water abstraction 


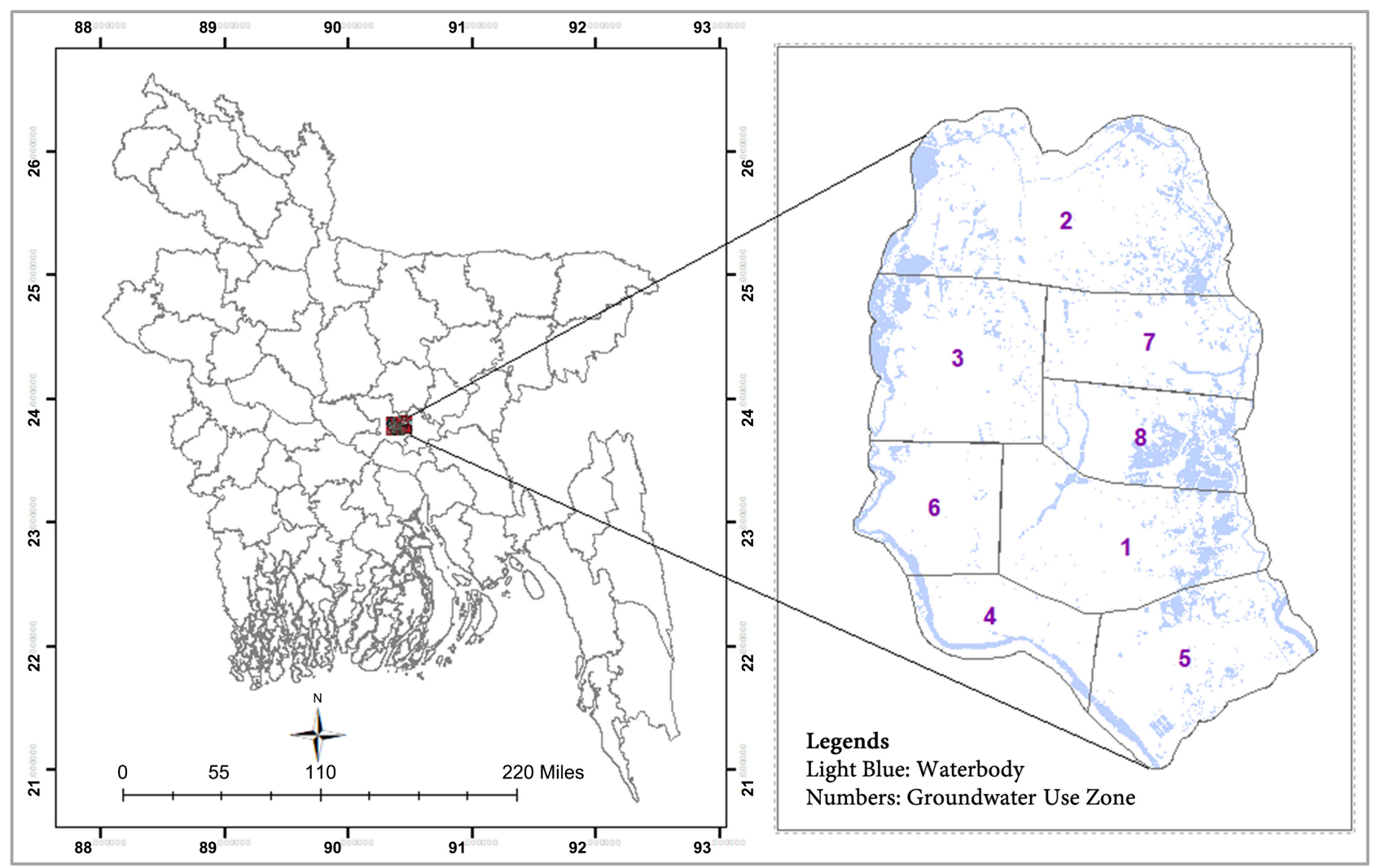

(a)

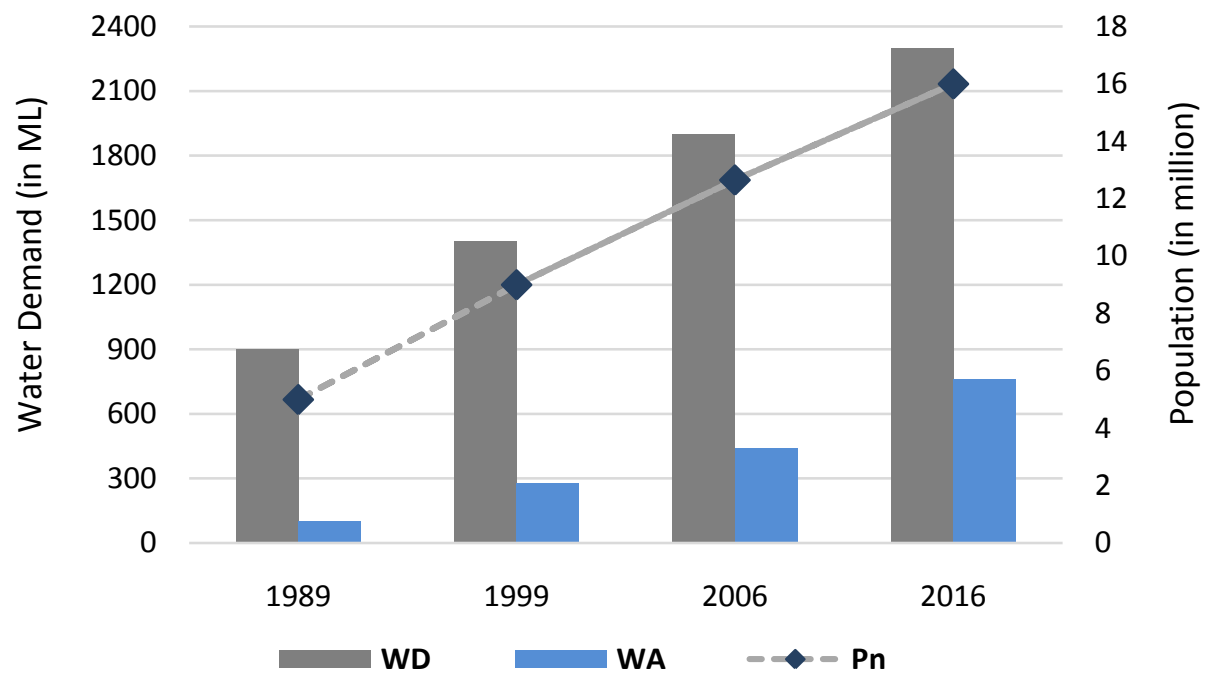

(b)

Figure 1. Study site: (a) Location and (b) Urban population, water demand, and water abstraction wells. Note: WD, water demand; WA, water abstraction wells; Pn, population.

wells. Figure 1(b) shows the trend of an increase in urban population and water demand.

The study uses temporal land cover, SWL, and water abstraction data. It should be noted that this study uses data of 1989, 1999, 2006 and 2016 because groundwater data are available for these years. For evaluating the proposed ap- 
proach, the entire study area is divided into eight major water use zones (Figure 1(a)). Tejgaon and Motijheel are aggregated as major industrial and commercial zone and categorized as zone 1. On the contrary, the other zones (Uttara-Zone 2, Mirpur-Zone 3, Old Dhaka-Zone 4, Jatrabari/Demra-Zone 5, Dhanmondi/Mohammadpur-Zone 6, Kuril/Bashundhara-Zone 7, and Badda/Gulshan-Zone 8) are classified as residential and mixed water-use zones. Finally, this study evaluates the relationships between changes in groundwater and several other important factors.

\section{Assessment of the Changes in Groundwater}

This study assesses the changes in groundwater focusing on the implications of urbanization, land cover change, water abstraction, and its use. In the following sections, first, multi-year land cover maps are prepared; second, water abstraction pattern is analyzed; third, the fluctuations in water level are investigated, and finally, the relationships of changes in groundwater level are evaluated in terms of several important factors.

\subsection{Evaluation of the Influence of Urbanization and Land Cover Changes}

Urbanization and land cover changes seem to affect groundwater resources [10] [11] [12]. This study aims to evaluate their impact on the changes in the groundwater level. Thus, multi-year land cover maps are used to detect urbanization and major urban land cover types. This study uses a decision tree algorithm to classify Landsat images into three types i.e., urban built-up, water and pervious surface. The temporal land cover classification accounts for an overall accuracy of $94 \%$. The size of the built-up area is widely used as an indicator of urbanization (Ebrahimian et al., 2016). In this study, the growth of the urban built-up area is used to investigate urbanization. The changes in land cover characteristics influence infiltration and groundwater water systems. The infiltration of rainfall in the form of recharge is a significant source of groundwater resources [37], and groundwater recharge is related to the characteristics of the land cover classes [38]. The urban sealed areas modify infiltration [15], therefore, the residential, commercial, industrial and other built-up areas are classified as built-up areas. Recharge to the main aquifer occurs via areas covering vegetation, trees, gardens, open space and bare lands, therefore, these are categorized as pervious surfaces. In contrast, there is a close interaction between surface and groundwater water systems [39]. Therefore, the urban built-up, pervious surfaces and surface water are classified as the major land cover classes in this study.

\subsection{Assessment of Groundwater Abstraction}

The over-extraction of groundwater water is one of the significant factors of a rapid drop in the water level [17] [18]. It is important to consider the spatial distribution of water abstraction wells and the rate of water withdrawal for eva- 
luating the changes in the groundwater level. In this investigation, the spatial coverage of the water abstraction wells is collected from the Dhaka Water Supply and Sewerage Authority (DWASA). The domestic, industrial and commercial usage accounts for the major categories of water abstraction in this study area. To meet municipal water demand the DWASA operates 760 water abstraction wells Moreover, approximately 2000 water abstraction wells are being operated by private sectors. The study area accounts for about 1000 private industrial and commercial wells and about 1000 private domestic wells. It should be noted that some of the water abstraction wells are not functioning. First, the zone-specific number of different types of functional wells for 1989, 1999, 2006 and 2016 are computed. Second, the numbers, thus computed, are correlated with the mean groundwater level.

\subsection{Mapping the Fluctuations in Groundwater Level}

In this section, the fluctuations in water level are mapped using groundwater monitoring data, which are collected from the Bangladesh Water Development Board (BWDB), and the DWASA. It should be noted that the study area has a total 14 groundwater monitoring wells but the periods of installation of the wells are dissimilar. Moreover, multi-year data is missing for several observation wells. The study area lacks adequate spatial coverage of groundwater data. In this investigation, the SWL data are used for preparing groundwater level fluctuation maps. Using ArcGIS, the interpolation technique, kriging (Equation (1)) is applied to map spatial variations in the water level. The DWASA coordinates the installation of the water abstraction wells and keeps a record of the SWL that covers a relatively large spatial coverage. The depth of the SWL represents the historical behavior of the groundwater [40]. Thus, this study uses the SWL data for preparing water level fluctuation maps.

$$
\hat{Z}\left(s_{0}\right)=\sum_{i=1}^{N} \lambda_{i} Z\left(s_{i}\right)
$$

where $N$ is the number of measured values, $s_{0}$ is the predicted location, $\lambda_{i}$ is the unknown weight for the measured value at the $i$-th location and $Z\left(s_{i}\right)$ is the measured value at the $i$-th location.

\subsection{Exploring Factors Affecting the Changes in Groundwater Level}

This section describes the approach used to explore the factors affecting the groundwater level in relation to several important variables. First, using ArcGIS, the Getis-Ord $G_{i}^{*}$ statistic is applied to identify the hot and cold spots of the water levels (Equation (2)). It is a powerful tool to presents the local spatial variability. The z-score of the Getis-Ord $G_{i}^{*}$ indicates the statistical significance of the clustering. Its value accounts for both positive and negative. The highest positive $z$-scores indicate statistically significant hotspot, the lowest negative $\mathrm{z}$-scores indicate cold spot and a value of 0 indicates insignificant clustering [41]. After identifying the hotspots, its association with land cover types and water 
abstraction patterns are evaluated.

$$
G_{i}^{*}=\frac{\sum_{j=1}^{n} w_{i, j} x_{j}-\bar{X} \sum_{j=1}^{n} w_{i, j}}{S \sqrt{\frac{n \sum_{j=1}^{n} w_{i, j}^{2}-\left(\sum_{j=1}^{n} w_{i, j}\right)^{2}}{n-1}}}
$$

where $w_{i, j}$ is the spatial weight between feature $i$ and $j, x_{j}$ is the attribute value for feature $j, n$ is the total number of features, $\bar{X}$ and $S$, mean and standard deviation of the feature values.

Finally, the zone-specific mean SWL is used as the dependent variable, the land cover classes (\% of urban built-up, water and pervious surface) and the numbers of functional water abstraction wells (industrial, commercial and domestic) are used as the explanatory variables for evaluating the interactions. The conventional Ordinary Least Squares (OLS) regression model is used to detect the relationship between changes in groundwater and several important factors. The p-values are delineated to assess the significance of the relationships.

\section{Results and Discussion}

\subsection{Urbanization and Land Cover Changes}

Figure 2 presents a visual comparison of the multi-year land cover types from 1989 to 2016. Figure 2(a) presents the changes in urban built-up areas. One of the important indicators of urbanization, the urban built-up areas increased from $12.81 \%$ in 1989 to $39.19 \%$ in 2016 , with an annual increasing rate of $0.98 \%$. Outward expansion of built-up areas indicates that the city is experiencing urbanization. Figure 2(b) shows the changes in water areas. It is evident that in 1989 the study area contained large areas of water. However, urbanization influenced the distribution of surface water thus the total water area decreased from $38.47 \%$ in 1989 to $12.70 \%$ in 2016, with an annual decreasing rate of $0.95 \%$. Figure 2 (c) presents the changes in pervious surfaces. Note that in 1989, the pervious surfaces dominated in the central part of the study area. However, gradual domination by the urban built-up areas was noticed in the later years. In contrast, the prevailing water areas of 1989 were transited into pervious surfaces. The investigation confirms that pervious surfaces decreased in the central part. But this land cover increased in the periphery of the study area, therefore, the total proportional change in the previous surface is not significant.

\subsection{Water Abstraction and the Changes in Groundwater}

Table 1 summarizes the temporal growth of water abstraction wells from 1989 to 2016. It presents a gradual increase in all types of water abstractions. In the groundwater-dependent cities, water abstraction increases with an increase in urbanization and water demand. In this study area, an increase in the urban population resulted in high water demand (Figure 1(b)), and thereby increased the trend of groundwater abstraction by installing many wells. The DWASA is responsible to supply water for the municipality. However, the DWASA hardly 


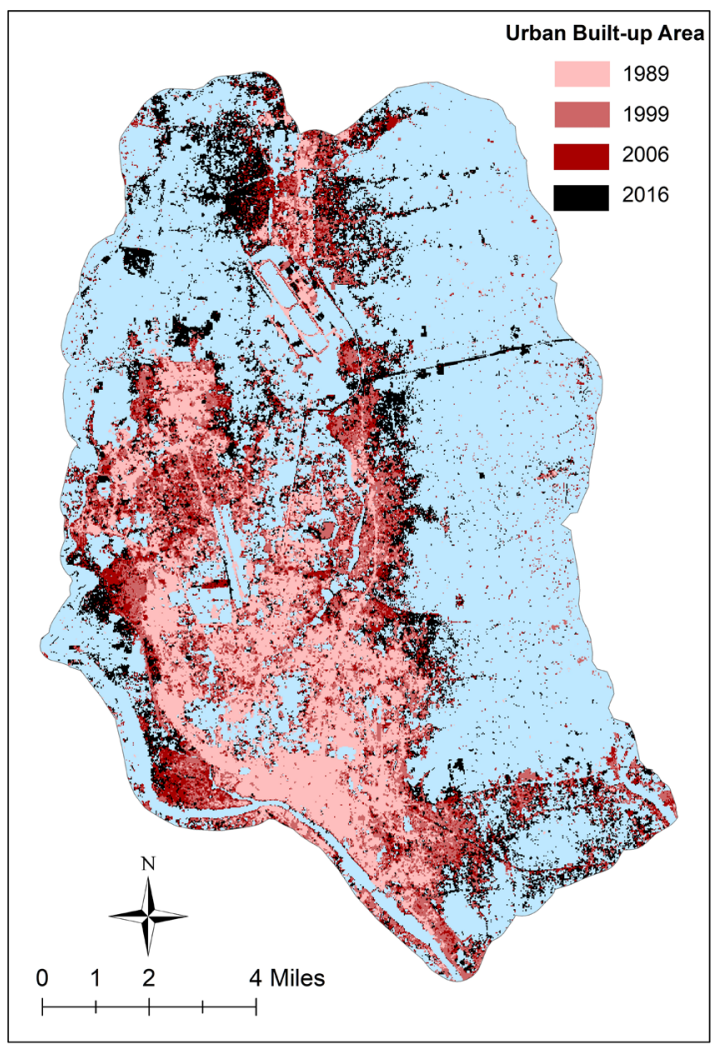

(a)

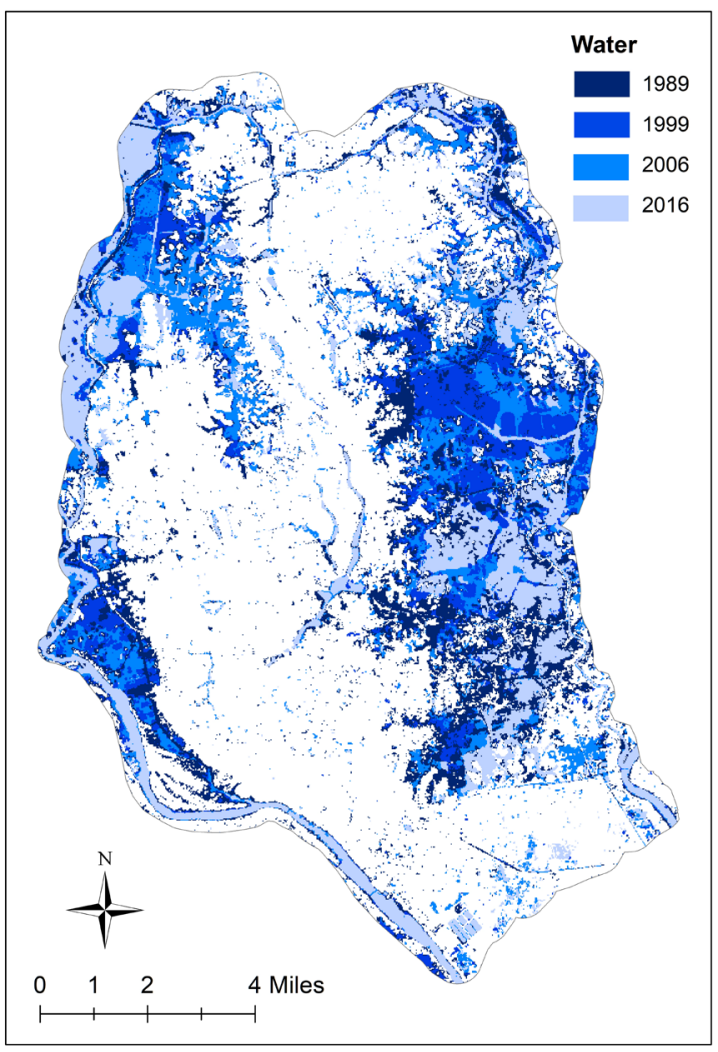

(b)

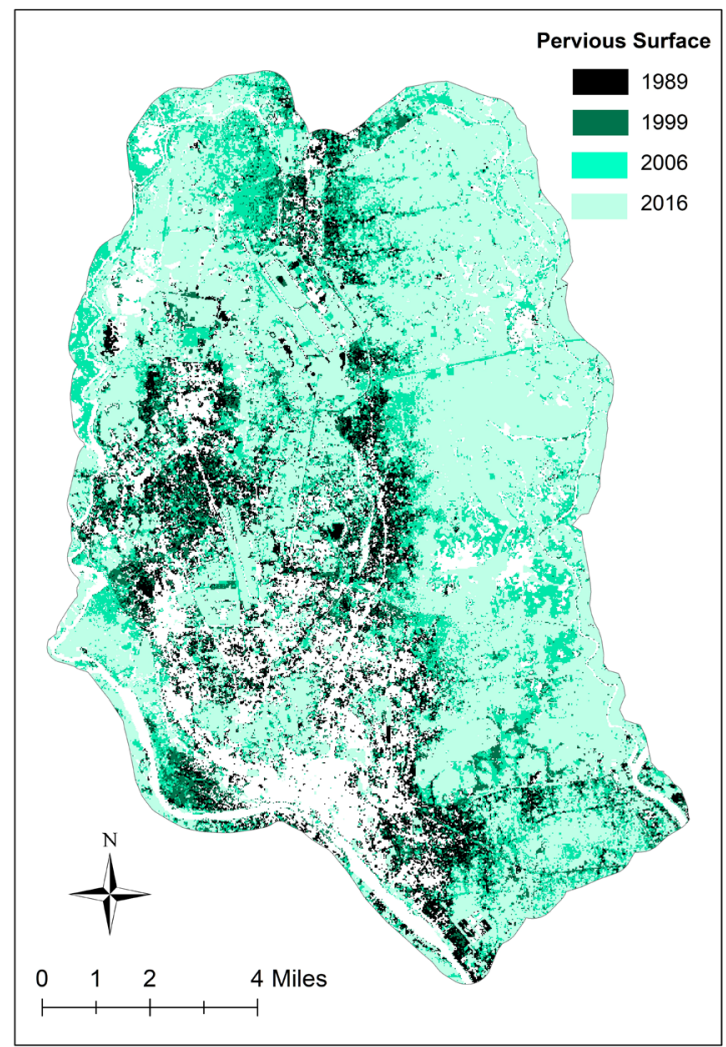

(c)

Figure 2. Urbanization and spatial distribution of major land cover types (1989-2016). 
Table 1. Zone specific water use and the number of water abstraction wells.

\begin{tabular}{|c|c|c|c|c|c|c|c|c|c|c|c|c|}
\hline \multirow{2}{*}{$\begin{array}{l}\text { Zone } \\
\text { ID }\end{array}$} & \multicolumn{4}{|c|}{ Municipal } & \multicolumn{4}{|c|}{ Industrial } & \multicolumn{4}{|c|}{ Commercial } \\
\hline & 1989 & 1999 & 2006 & 2016 & 1989 & 1999 & 2006 & 2016 & 1989 & 1999 & 2006 & 2016 \\
\hline 1 & 19 & 113 & 196 & 339 & 11 & 25 & 45 & 58 & 9 & 32 & 75 & 149 \\
\hline 2 & 6 & 12 & 32 & 94 & 0 & 0 & 1 & 13 & 2 & 5 & 30 & 66 \\
\hline 3 & 13 & 63 & 145 & 288 & 2 & 12 & 45 & 75 & 4 & 22 & 100 & 169 \\
\hline 4 & 15 & 50 & 75 & 134 & 0 & 0 & 1 & 5 & 0 & 2 & 7 & 40 \\
\hline 5 & 4 & 26 & 49 & 96 & 0 & 2 & 3 & 26 & 0 & 6 & 12 & 45 \\
\hline 6 & 13 & 54 & 134 & 249 & 0 & 1 & 2 & 9 & 4 & 13 & 35 & 95 \\
\hline 7 & 2 & 10 & 15 & 46 & 0 & 0 & 0 & 1 & 0 & 3 & 15 & 43 \\
\hline 8 & 3 & 15 & 51 & 120 & 1 & 2 & 5 & 22 & 0 & 0 & 18 & 99 \\
\hline Total & 75 & 343 & 697 & 1366 & 14 & 42 & 102 & 209 & 19 & 83 & 292 & 706 \\
\hline
\end{tabular}

meets the required water demand; therefore, a large number of private wells also operate to meet the demand for domestic water. The investigation confirms 18 times increase in the municipal water abstraction, as the numbers of wells increased from a total of 75 wells in 1989 to a total 1366 wells in 2016. The number of industrial water abstraction increased 15 times as the number of wells of this category increased from 14 to 209 from 1989 to 2016. In contrast, the commercial water abstraction increased 37 times as the number of wells increased from 19 to 706 between the 1989s and 2016s. It should be noted that industrial and commercial water use differs from domestic water use, therefore, these are selfsupplied in many countries [42]. In Dhaka City, industrial and commercial water uses are also self-supplied. In conclusion, the increase in the municipal, industrial and commercial water abstraction wells indicates the increase in water demand thus results in a high abstraction of groundwater.

Figure 3 presents a visual comparison of the spatiotemporal groundwater levels. In 1989, the highest water level was $18.37 \mathrm{~m}$ that reached $43.94 \mathrm{~m}$ in 1999. During the 10 years, an annual drop in the water level was $2.5 \mathrm{~m}$. A gradual drop in the groundwater level is also obvious in later years. The temporal maps show that the groundwater levels continued to drop in the entire study area. However, the changes in the water levels are locally variable. The highest drop in the groundwater level is noticeable in the central part of the study area. In contrast, a low drop in the water level is observed in the northern and periphery of the study area from 1989 to 2006. In 2016, the entire study area showed relatively a high drop in the groundwater level with a minimum local variation.

Figure 4 presents the changes in the mean groundwater level by zones during the 27 years (1989 to 2016). A rapid drop in the water level is noticed in each of the water supply zones. However, the water level highly dropped in Zone 1 compared to the other zones because the major industrial and commercial activities are concentrated in Zone 1. Zone 3 and Zone 8 also show a high gradual drop in the water level, because of the expansion of industrial and commercial activities 


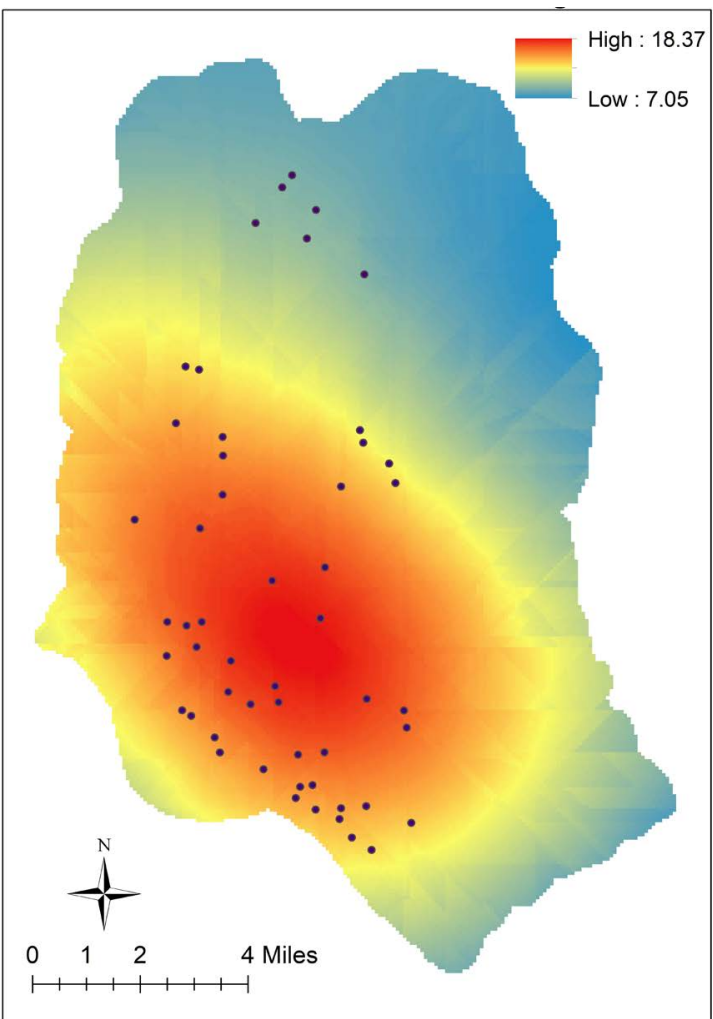

(a)

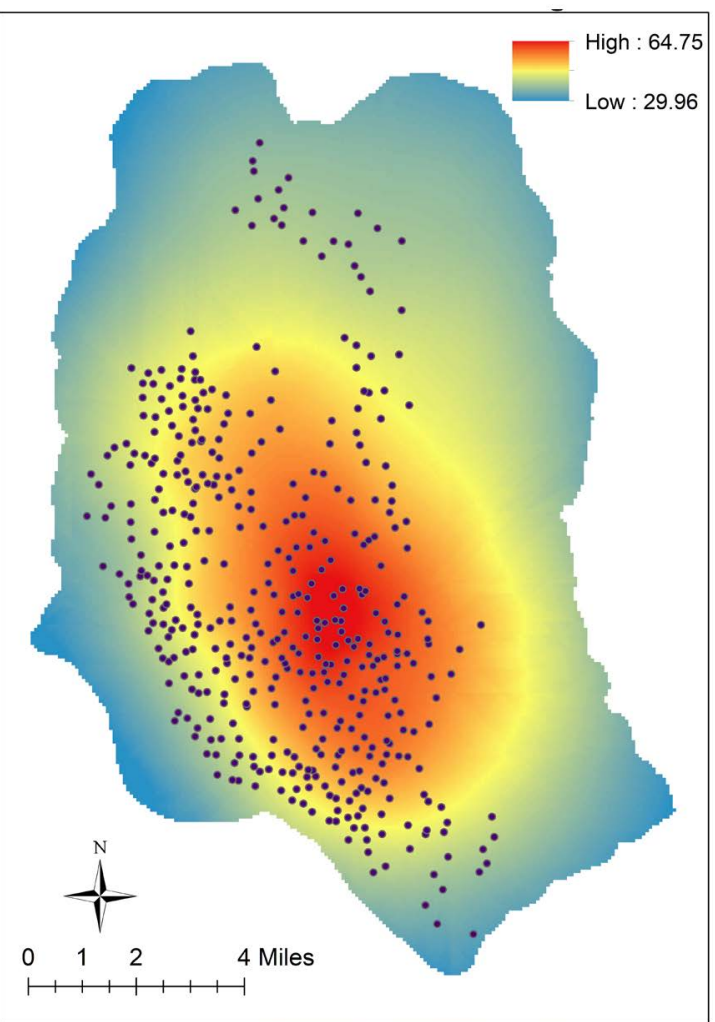

(c)

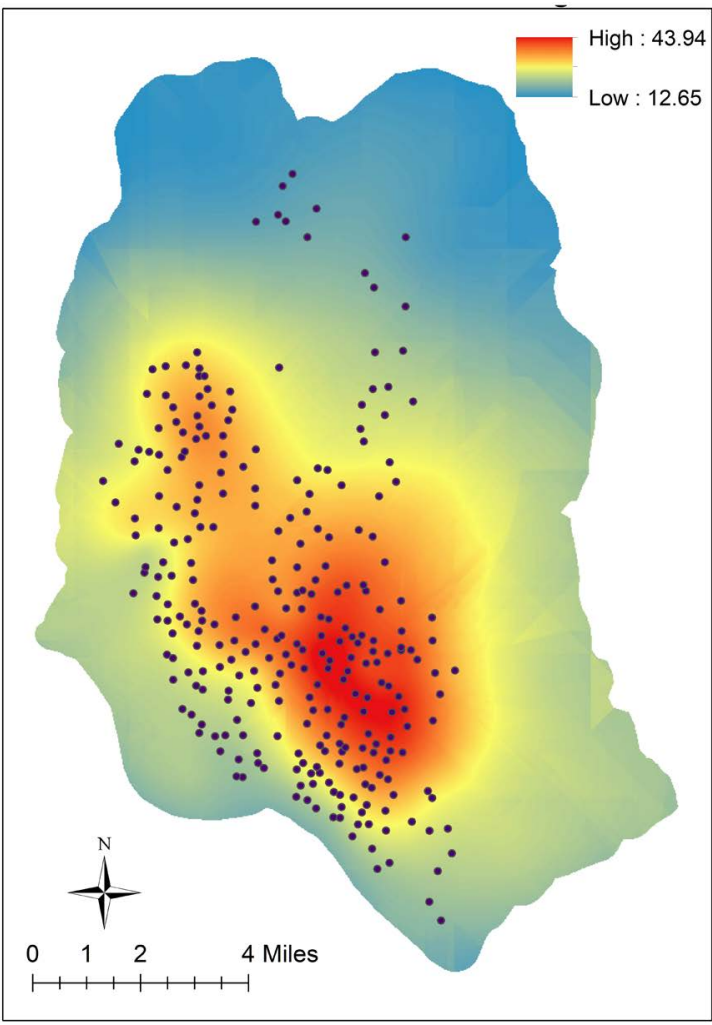

(b)

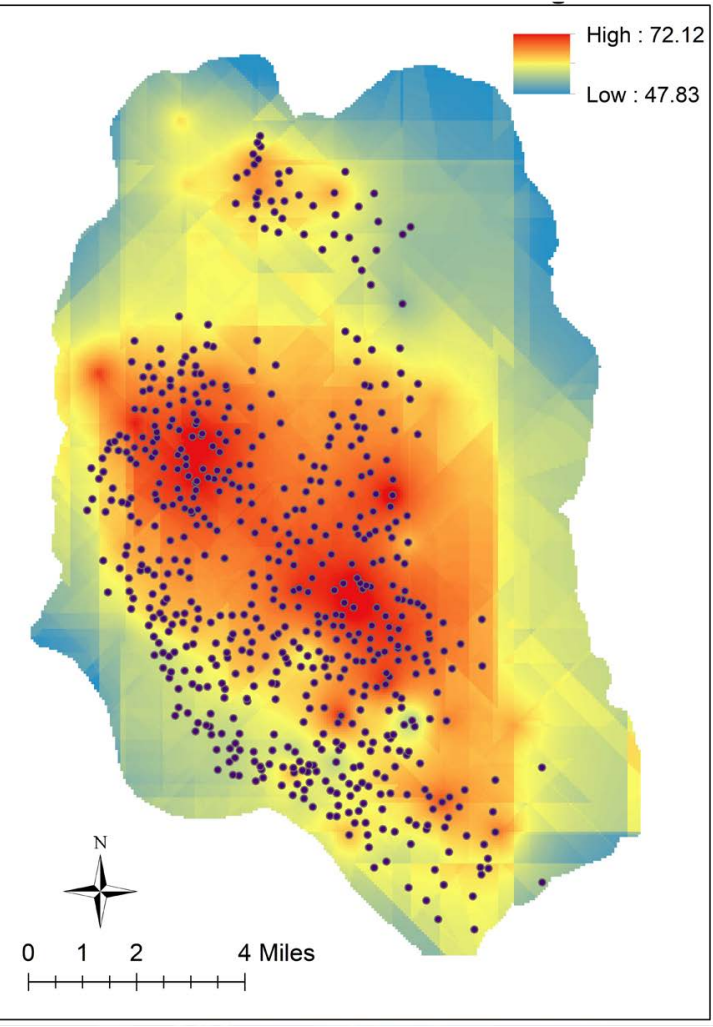

(d)

Figure 3. Local spatial variation in the water level in: (a) 1989, (b) 1999, (c) 2006 and (d) 2016 (Points represent location of water abstraction wells). 


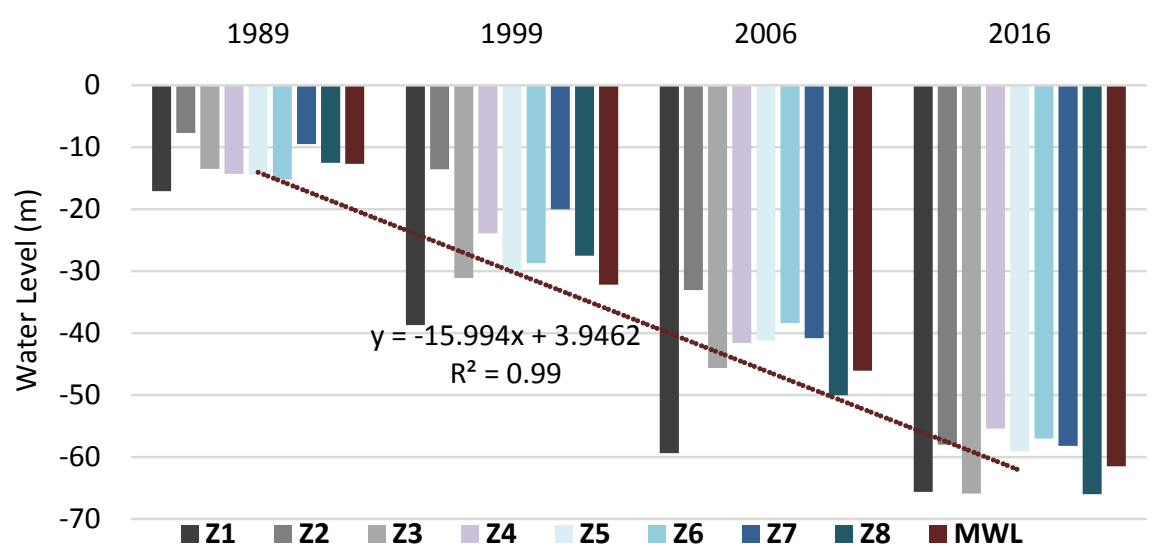

Figure 4. Mean groundwater level by zones. Note: $Z 1,2, \ldots, n$ represent zone ID and MWL represents mean water level.

and an increase in water abstraction (Table 1). In contrast, a low drop in the groundwater level is noticed in Zone 2. During the 27-year, the overall mean water levels dropped significantly $(\mathrm{p}<0.05)$ from 12.67 to $61.49 \mathrm{~m}$ with an annual drop of $1.81 \mathrm{~m}$. The study area shows high changes in the water level, probably due to the over-extraction and lack of regulations on groundwater use. The temporal overview demonstrates that the groundwater level continued to drop in the entire study area. However, the highest drop in the water level was noticed in the major industrial and commercial sites that continued to expand in surrounding areas.

\subsection{Hotspot of the Depletion in Groundwater Levels}

Figure 5 presents a visual comparison of the spatiotemporal hotspots of the depletion of the groundwater level. The statistically significant hotspots are mostly concentrated in Zone1, the central part of the study area. Moreover, several statistically significant hot spots are noticed in Zone 6, Zone 3, and Zone 8 in different years. In contrast, the statistically significant cold spots are consistently observed in Zone 2, the northern part of the study area. The results indicate that the overall extent of the hotspots is variable to a temporal scale, but Zone 1 shows the consistent hotspot in all of the study years. Gradual development in the industrial and commercial (IC) water abstraction wells (Table 1) indicates Zone 1 as the major hub of industrial and commercial activities. The water demand is high for the IC activities compared to other activities.

It should be noted that in Bangladesh nearly $70 \%$ of the textile industries are located around or in Dhaka [31]; moreover, the textile industry is the main user of industrial water [43]. The production of one-kilogram fabric requires 250 to 300 liters water that is equivalent to daily water use for two people in Dhaka [31] [44]. It is obvious that water demand and consumption is higher for the industry compared to the domestic water demand; therefore, Zone 1 shows a consistent hotspot of water level depletion. This study evaluates the influence of industrialization on the groundwater levels; thus delineates the coefficient of determinations 


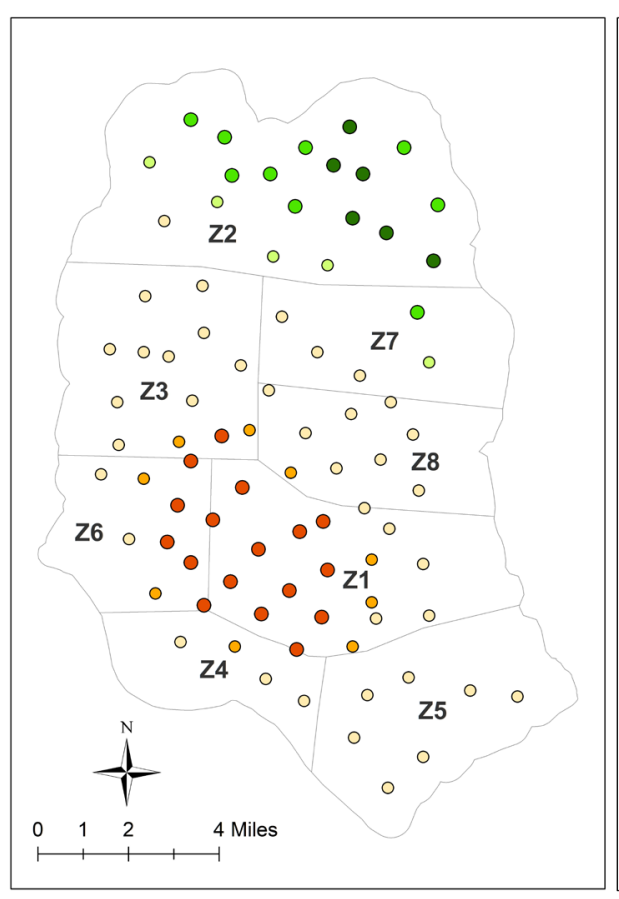

(a)

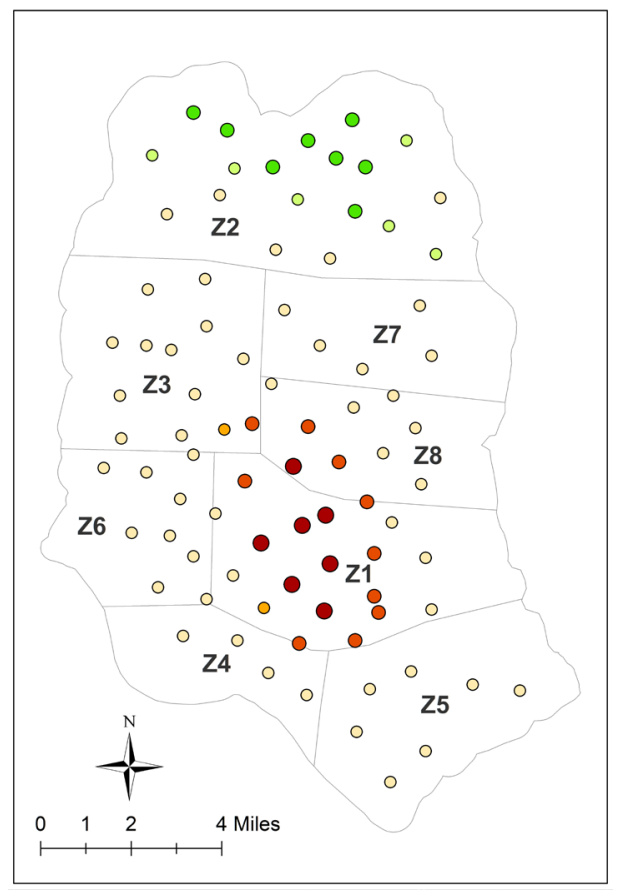

(c)

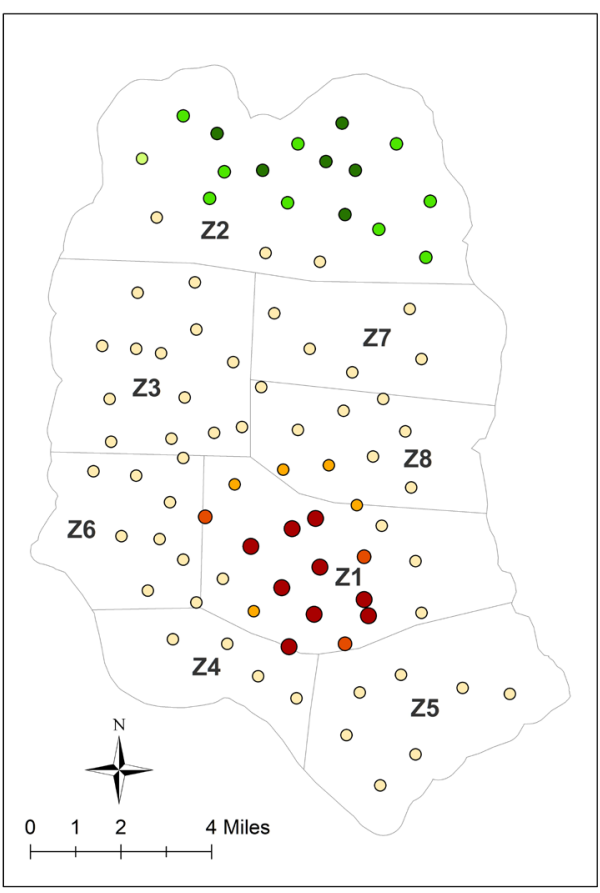

(b)

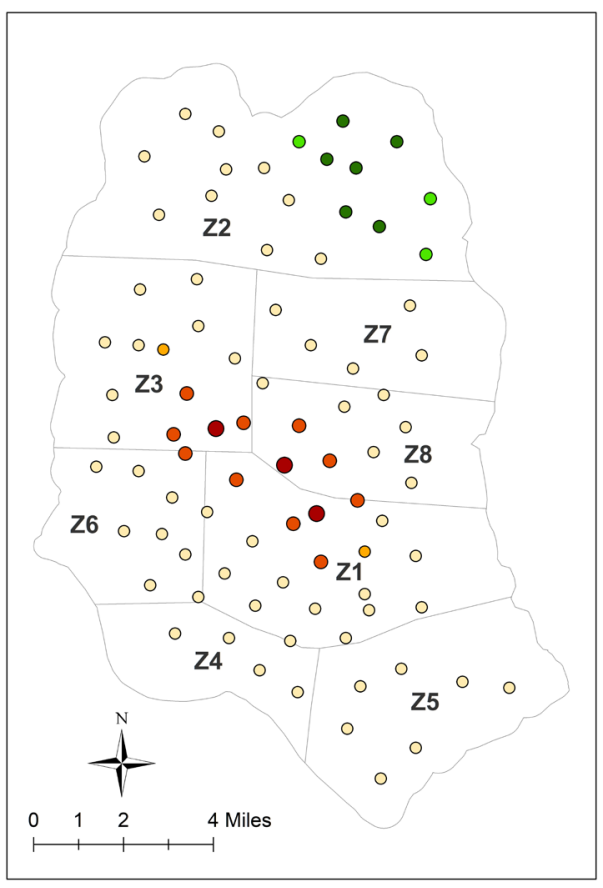

(d)
Cold Spot-99\% Confidence
Cold Spot-95\% Confidence
$\checkmark$ Cold Spot-90\% Confidence
3 Not Significant
$\checkmark$ Hot Spot-90\% Confidence
Hot Spot-95\% Confidence
Hot Spot-99\% Confidence

Figure 5. Hotspot of groundwater depletion in: (a) 1989, (b) 1999, (c) 2006 and (d) 2016. 
between the changes in water level and proximity to the industrial center along with the four directions as shown in Figure 6. The results show significant $(\mathrm{p}<$ $0.05)$ strong negative correlation between them. The investigations show that the water level decrease with an increase in the distance from IC zone. In contrast, water levels highly drop in proximity to the IC zone. In conclusion, it is obvious that industrial and commercial water abstraction highly influences groundwater level compared to domestic/municipal water abstraction.

\subsection{Factors Influencing the Changes in Water Level}

Several important factors including urbanization, land cover, water use, and water abstraction influence in the changes in groundwater (Islam et al., 2017; Arfanuzzaman and Atiq Rahman, 2017; Restiani [31]; Baillieux et al., 2015), thus, this study focuses on the assessment of these factors influencing groundwater in a typical urban environment. The investigation confirms that the study area experiences urbanization and involves land cover changes (Figure 2). The study area shows an increasing trend of the urban population, water demand and water abstraction (Figure 1(b)). In contrast, a significant drop in the groundwater water level is obvious as shown in Figure 3, Figure 4.

The interactions between changes in land cover types and groundwater levels are shown in Table 2. The coefficient of determination between urban built-up areas and water level shows a significant $(\mathrm{p}<0.01)$ strong positive correlation

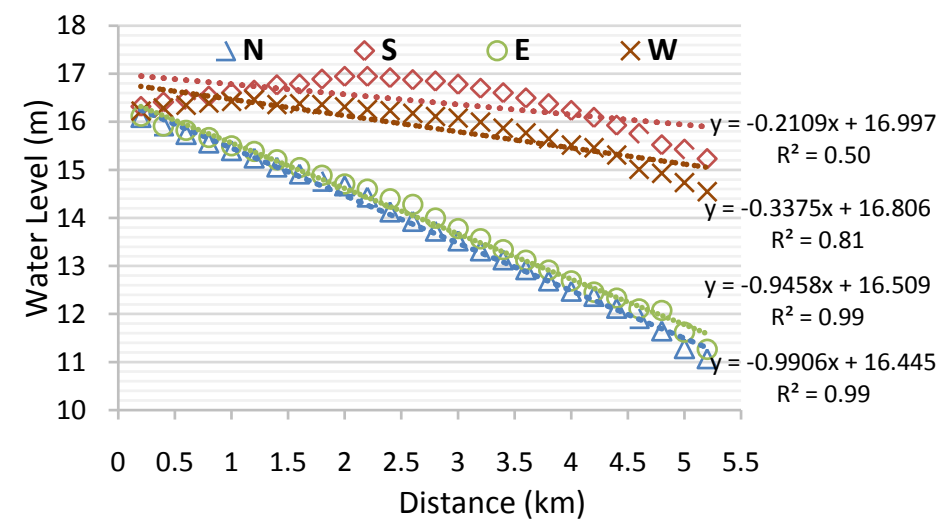

(a)

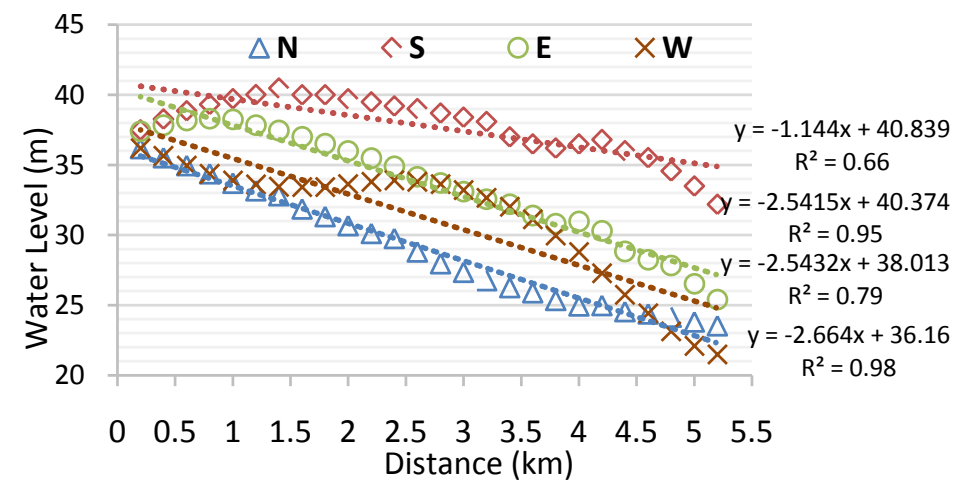

(b) 


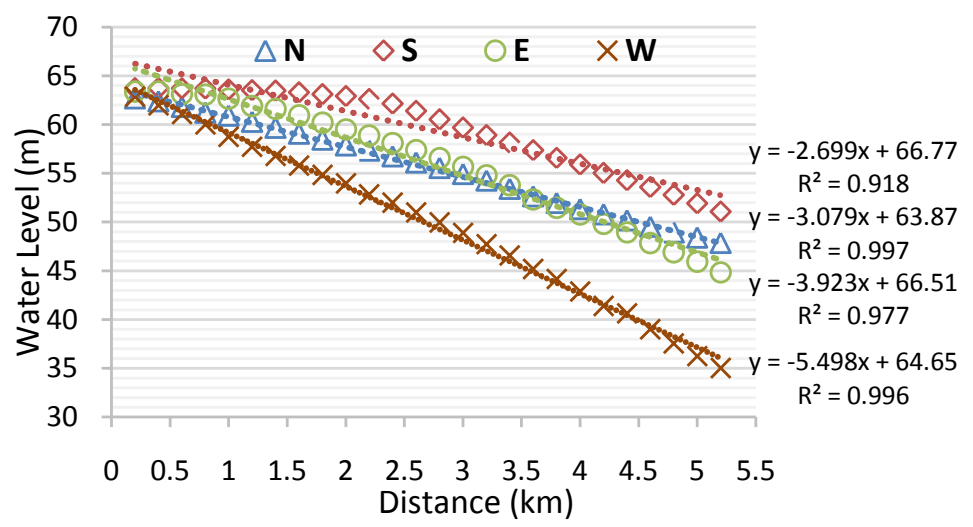

(c)

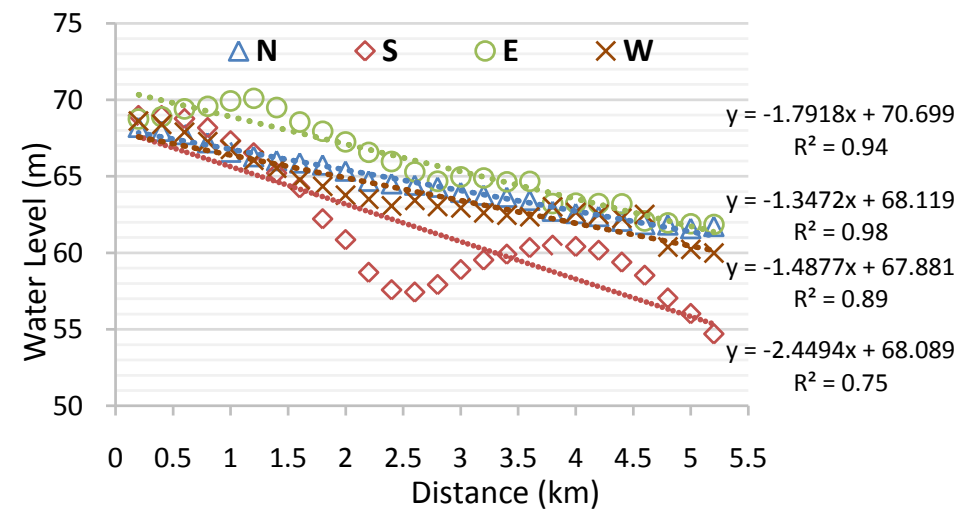

(d)

Figure 6. Relationship between proximity to industrial zone and water level in (a) 1989, (b) 1999, (c) 2006 and (d) 2016. Note: N, north; S, south; E, east and W, west.

Table 2. Coefficients of determination between land cover types and groundwater level.

\begin{tabular}{ccc}
\hline Land Cover Types & Coefficient of Determinations $\left.\mathbf{~}^{2}\right)$ \\
\hline Urban Built-up & 0.98 & \\
Pervious Surface & 0.00 & $\mathrm{p}<0.05$ \\
Water & -0.97 & \\
\hline
\end{tabular}

$\left(\mathrm{R}^{2}=0.98\right)$. In contrast, the interaction with surface water shows significant $(\mathrm{p}<$ $0.01)$ strong negative correlation $\left(\mathrm{R}^{2}=0.97\right)$. The results show that the changes in pervious surfaces do not influence the groundwater level. It should be noted that various factors affect groundwater. However, the most important factor influencing groundwater is not stationary. The results of this study indicate that urban built-up and surface water areas are good indicators of exploring the changes in groundwater.

Table 3 shows the evaluation results of the influence of water abstraction on the groundwater level. The results indicate significant $(\mathrm{p}<0.05)$ strong positive correlations $\left(\mathrm{R}^{2} \geq 0.80\right)$ between the numbers of various water abstraction wells and the groundwater level. The experimental evaluation indicates that water abstraction has a high influence on the groundwater level compared to other 
Table 3. Coefficients of determination between water abstraction and mean groundwater level.

\begin{tabular}{ccc}
\hline Numbers of Water Abstraction Wells & Long-term linear coefficient of determinations $\left(\mathbf{R}^{2}\right)$ \\
\hline Municipal (public and private domestic) & 0.93 & $\mathrm{p}<0.05$ \\
Industrial & 0.90 & \\
Commercial & 0.86 & \\
Total (Combined all types of wells ) & 0.90
\end{tabular}

Table 4. Coefficient of determinations between urban growth, water demand, and water levels.

\begin{tabular}{cccc}
\hline Interactions & Equation & $\mathbf{R}^{2}$ & p-value \\
\hline UB - Pn & $y=0.4271 x-0.3569$ & 0.98 & 0.009 \\
Pn - WD & $y=128.28 x+257.25$ & 0.99 & 0.000 \\
WD - WA & $y=0.451 x-338.33$ & 0.95 & 0.023 \\
WA - WL & $y=0.0724 x+9.5464$ & 0.96 & 0.021 \\
\hline
\end{tabular}

Note: UB, urban built-up; Pn, population; WD, water demand; WA, water abstraction and WL, water level.

parameters. The results corroborate to earlier assumptions that groundwater abstraction has a significant impact on water levels [17] [18].

Table 4 shows the coefficient of determinations between urban growth factors and water levels. The size of the urban built-up area is one of the significant indicators of urbanization [45], which shows a strong positive correlation with growth in the urban population. Per capita water demand increases with an increase in the urban population [20], therefore, it shows a strong positive correlation $\left(R^{2}=0.99\right)$ between urban population and water demand. The increase in water demand accelerates water abstraction, thus results in a strong positive correlation $\left(\mathrm{R}^{2}=0.95\right)$ between them. In contrast, the high water abstraction results in a rapid drop in the groundwater level [31]. The result of this study shows a significant $(\mathrm{p}<0.05)$ strong positive correlation $\left(\mathrm{R}^{2}=0.96\right)$ between water abstraction and the changes in water level. In conclusion, urbanization induces changes in various parameters, which affect the groundwater system. A sustainable water management plan is important to secure future urban water demand.

\section{Conclusions}

Groundwater is one of the important components of the environment. Several factors affect groundwater, however, the existing studies often evaluate the changes in groundwater at short temporal scales, and rarely investigate the local spatial changes and their interactions with urbanization induced growth factors. This study presents an approach of investigating the changes in groundwater level in relation to several important factors, e.g., urbanization, land cover, water demand, water abstraction, and its use. In this study, a typical urban area is se- 
lected for evaluating the urbanization and its implication in the changes of groundwater. This study uses multi-year datasets of land cover types, SWL, water demand, abstraction, and its use and evaluates a long-term perspective of the changes in urban groundwater. The results of this study confirm that the changes in urban groundwater are characterized by spatial and temporal variation thus groundwater is nonstationary across space. The results indicate a decrease in surface water and an increase in the urban built-up area, which is one of the important indicators of urbanization. The city experiences a progressive drop in the groundwater level. However, the hotspot of the depletion of groundwater is noticeable in Zone 1 and its surroundings. Because this zone comprises of many industrial and commercial activities; the extensive withdrawal of groundwater for those uses accelerates to a rapid depletion in the groundwater.

The results indicate a rapid drop in the groundwater level with an increase in urban built-up areas or urbanization. In contrast, the changes in surface water are negatively correlated to the levels of groundwater. It should be noted that this study finds no significant impact on the groundwater level for the changes in pervious areas. However, the investigation of the influence of groundwater abstraction indicates it to be the major driving factor of a rapid drop of groundwater in an urban environment. The results also indicate that there is a significant negative correlation between proximity to the industrial zone and the groundwater level. The proposed approach of assessing the changes in groundwater is of significance to facilitate the managing of this scarce resource in various cities. This study evaluates several important driving factors of changes in groundwater; however, some other driving forces such as climate, the volume of water abstraction and aquifer recharge should be considered in future studies. It should also be noted that the study area lacks large spatial coverage of the groundwater monitoring data that limits a comprehensive local level analysis. Local spatial information is important in the application of urban planning and water resource management. Thus, this study urges intensive and frequent monitoring of the groundwater at the local-scale to secure and manage future water demand.

\section{Acknowledgements}

The authors thank the US Geological Survey (USGS) for making the Landsat datasets publicly available. The authors also thank the BWDB and DWASA for providing groundwater data.

\section{Conflicts of Interest}

The authors declare no conflicts of interest regarding the publication of this paper.

\section{References}

[1] Tom, G., et al. (2012) Water Balance of Global Aquifers Revealed by Groundwater 
Footprint. Nature, 488, 197-200. https://doi.org/10.1038/nature11295

[2] Minnig, M., et al. (2017) Impact of Urbanization on Groundwater Recharge Rates in Dübendorf, Switzerland. Journal of Hydrology, 563, 1135-1146. https://doi.org/10.1016/j.jhydrol.2017.09.058

[3] Moeck, C., et al. (2017) Characterization of a Managed Aquifer Recharge System Using Multiple Tracers. Science of the Total Environment, 609, 701-714. https://doi.org/10.1016/j.scitotenv.2017.07.211

[4] Morris, B., et al. (2007) Using Linked Process Models to Improve Urban Groundwater Management: An Example from Doncaster England. Water and Environment Journal, 21, 229-240. https://doi.org/10.1111/j.1747-6593.2006.00067.x

[5] Rasmussen, T.C. (2011) Surface and Subsurface Waters. In: Gliński, J., Horabik, J. and Lipiec, J., Eds., Encyclopedia of Agrophysics, Springer, Dordrecht, 874-877. https://doi.org/10.1007/978-90-481-3585-1_167

[6] Drangert, J.O. and Cronin, A. (2004) Use and Abuse of the Urban Groundwater Resource: Implications for a New Management Strategy. Hydrogeology Journal, 12, 94-102. https://doi.org/10.1007/s10040-003-0307-z

[7] Howard, K.W.F. (2002) Urban Groundwater Issues-An Introduction. In: Current Problems of Hydrogeology in Urban Areas, Urban Agglomerates and Industrial Centres, Springer, Dordrecht, 1-15. https://doi.org/10.1007/978-94-010-0409-1_1

[8] Stephen, F. (2020) Global Policy Overview of Groundwater in Urban Development-A Tale of 10 Cities. Water, 12, 456. https://doi.org/10.3390/w12020456

[9] Esteban, E. and Dinar, A. (2013) Modeling Sustainable Groundwater Management: Packaging and Sequencing of Policy Interventions. Journal of Environmental Management, 119, 93. https://doi.org/10.1016/j.jenvman.2012.12.047

[10] Khazaei, E., Mackay, R. and Warner, J.W. (2004) The Effects of Urbanization of Groundwater Quantity and Quality in the Zahedan Aquifer, Southeast Iran. Water International, 29, 178-188. https://doi.org/10.1080/02508060408691767

[11] Arfanuzzaman, M. and Atiq Rahman, A. (2017) Sustainable Water Demand Management in the Face of Rapid Urbanization and Ground Water Depletion for Social-Ecological Resilience Building. Global Ecology and Conservation, 10, 9-22. https://doi.org/10.1016/j.gecco.2017.01.005

[12] Uddameri, V., Singaraju, S. and Hernandez, E. (2014) Impacts of Sea-Level Rise and Urbanization on Groundwater Availability and Sustainability of Coastal Communities in Semi-Arid South Texas. Environmental Earth Sciences, 71, 2503-2515. https://doi.org/10.1007/s12665-013-2904-Z

[13] Grimm, N., et al. (2008) Global Change and the Ecology of Cities. Science, 319, 756-760. https://doi.org/10.1126/science.1150195

[14] Song, X., et al. (2014) Rapid Urbanization and Changes in Spatiotemporal Characteristics of Precipitation in Beijing Metropolitan Area. Journal of Geophysical Research: Atmospheres, 119, 11250-11271. https://doi.org/10.1002/2014JD022084

[15] Baillieux, A., et al. (2015) Assessing Groundwater Quality Trends in Pumping Wells Using Spatially Varying Transfer Functions. Hydrogeology Journal, 23, 1449-1463. https://doi.org/10.1007/s10040-015-1279-5

[16] Xue, L., Guomin, L. and Yuan, Z. (2014) Identifying Major Factors Affecting Groundwater Change in the North China Plain with Grey Relational Analysis. Water, 6, 1581-1600. https://doi.org/10.3390/w6061581

[17] Hoque, M., Hoque, M. and Ahmed, K. (2007) Declining Groundwater Level and Aquifer Dewatering in Dhaka Metropolitan Area, Bangladesh: Causes and Quanti- 
fication. Hydrogeology Journal, 15, 1523-1534. https://doi.org/10.1007/s10040-007-0226-5

[18] Islam, M., et al. (2017) A Regional Groundwater-Flow Model for Sustainable Groundwater-Resource Management in the South Asian Megacity of Dhaka, Bangladesh. Hydrogeology Journal, 25, 617-637. https://doi.org/10.1007/s10040-016-1526-4

[19] Wada, Y., et al. (2016) Modeling Global Water Use for the 21st Century. Geoscientific Model Development, 9, 175-222. https://doi.org/10.5194/gmd-9-175-2016

[20] Bijl, D.L., et al. (2016) Long-Term Water Demand for Electricity, Industry and Households. Environmental Science and Policy, 55, 75-86.

https://doi.org/10.1016/j.envsci.2015.09.005

[21] Foster, S. (2001) The Interdependence of Groundwater and Urbanisation in Rapidly Developing Cities. Urban Water, 3, 185-192. https://doi.org/10.1016/S1462-0758(01)00043-7

[22] Chaudhuri, S. and Ale, S. (2014) Long-Term (1930-2010) Trends in Groundwater Levels in Texas: Influences of Soils, Landcover and Water Use. Science of the Total Environment, 490, 379-390. https://doi.org/10.1016/j.scitotenv.2014.05.013

[23] UN (2016) The World's Cities in 2016. Data Booklet, United Nations.

[24] Azharul Haq, K. (2006) Water Management in Dhaka. International Journal of Water Resources Development, 22, 291-311. https://doi.org/10.1080/07900620600677810

[25] Gain, A., et al. (2015) An Integrated Approach of Flood Risk Assessment in the Eastern Part of Dhaka City. Journal of the International Society for the Prevention and Mitigation of Natural Hazards, 79, 1499-1530.

https://doi.org/10.1007/s11069-015-1911-7

[26] Archive (2017) Population of Dhaka 2017. Archive, Dhaka.

[27] Nahar, M., et al. (2014) Investigation of Severe Water Problem in Urban Areas of a Developing Country: The Case of Dhaka, Bangladesh. Environmental Geochemistry and Health, 36, 1079-1094. https://doi.org/10.1007/s10653-014-9616-5

[28] Rahman, M., et al. (2013) Hydrogeological Analysis of the Upper Dupi Tila Aquifer, towards the Implementation of a Managed Aquifer-Recharge Project in Dhaka City, Bangladesh. Hydrogeology Journal, 21, 1071-1089. https://doi.org/10.1007/s10040-013-0978-z

[29] Hossain, N. and Bahauddin, K.M. (2013) Integrated Water Resource Management for Mega City: A Case Study of Dhaka City, Bangladesh. Journal of Water and Land Development, 19, 39-45. https://doi.org/10.2478/jwld-2013-0014

[30] Shams, S., et al. (2016) Physical Risk Assessment for Urban Water Supply in a Developing Country: A Case of Mega City Dhaka. Engineering Journal, 20, 23-31. https://doi.org/10.4186/ej.2016.20.3.23

[31] Restiani, P. (2016) Water Governance Mapping Report: Textile Industry Water Use in Bangladesh. Sweden Textile Water Initiative.

[32] Kazemi, G.A. (2011) Impacts of Urbanization on the Groundwater Resources in Shahrood, Northeastern Iran: Comparison with Other Iranian and Asian Cities. Physics and Chemistry of the Earth, 36, 150-159. https://doi.org/10.1016/j.pce.2010.04.015

[33] Akther, H., Ahmed, M.S. and Rasheed, K.B.S. (2009) Spatial and Temporal Analysis of Groundwater Level Fluctuation in Dhaka City, Bangladesh. Asian Journal of Earth Sciences, 2, 49-57. https://doi.org/10.3923/ajes.2009.49.57 
[34] Hu, X., et al. (2015) Land Use/Cover Change in the Middle Reaches of the Heihe River Basin over 2000-2011 and Its Implications for Sustainable Water Resource Management. PLOS ONE, 10, e0128960. https://doi.org/10.1371/journal.pone.0128960

[35] Morris, B., Seddique, A. and Ahmed, K. (2003) Response of the Dupi Tila Aquifer to Intensive Pumping in Dhaka, Bangladesh. Hydrogeology Journal, 11, 496-503. https://doi.org/10.1007/s10040-003-0274-4

[36] Rahman, S. and Hossain, F. (2008) Spatial Assessment of Water Quality in Peripheral Rivers of Dhaka City for Optimal Relocation of Water Intake Point. Water Resources Management: An International Journal, 22, 377-391. https://doi.org/10.1007/s11269-007-9167-y

[37] Kruse, E., et al. (2013) Recharge Assessment in an Urban Area: A Case Study of La Plata, Argentina. Hydrogeology Journal, 21, 1091-1100.

https://doi.org/10.1007/s10040-013-0981-4

[38] Scanlon, B.R., Reedy, R.C., Stonestrom, D.A., Prudic, D.E. and Dennehy, K.F. (2005) Impact of Land Use and Land Cover Change on Groundwater Recharge and Quality in the Southwestern US. Global Change Biology, 11, 1577-1593. https://doi.org/10.1111/j.1365-2486.2005.01026.x

[39] USGS (2017) Groundwater and Surface-Water Interactions. USGS Groundwater Information. https://water.usgs.gov/ogw/gwsw.html

[40] Luis, C.A., et al. (2014) Spatial and Temporal Evolution of the Static Water Level of the Cuauhtemoc Aquifer during the Years 1973, 1991 and 2000: A Geographical Approach. Journal of Geographic Information System, 6, 572-584. https://doi.org/10.4236/jgis.2014.65047

[41] ArcGIS (2018) How Hot Spot Analysis (Getis-Ord Gi*) Works. http://pro.arcgis.com/en/pro-app/tool-reference/spatial-statistics/h-how-hot-spot-a nalysis-getis-ord-gi-spatial-stati.htm

[42] Renzetti, S. (2003) Industrial and Commercial Water Demands. In: Agthe, D.E., Billings, R.B. and Buras, N., Eds., Managing Urban Water Supply, Springer, Dordrecht, 115-125. https://doi.org/10.1007/978-94-017-0237-9_8

[43] Désirée van, G., et al. (2014) Exploring the Water Management Sector in Bangladesh Trends, Opportunities and Practical Information. Netherlands Bangladesh Business Platform.

[44] Thomas, S. and Justin, A. (2015) An Analysis of Industrial Water Use in Bangladesh with a Focus on the Textile and Leather Industries. 2030 Water Resources Group, Washington DC.

[45] Ebrahimian, A., Wilson, B.N. and Gulliver, J.S. (2016) Improved Methods to Estimate the Effective Impervious Area in Urban Catchments Using Rainfall-Runoff Data. Journal of Hydrology, 536, 109-118. https://doi.org/10.1016/j.jhydrol.2016.02.023 